\section{Comparison of Luneau SA disposable and Goldmann applanation tonometer readings}

ACJ Baddon, SF Osborne, SA Quah, M Batterbury and D Wong

\begin{abstract}
Purpose To test the agreement of intraocular pressure (IOP) measurements made with Luneau SA applanators and Goldmann applanator.

Materials and Methods A single-blind crossover trial. IOPs were measured in both eyes of subjects with both applanators. Type of applanator was alternated to eliminate systematic bias. Multiple observers were used. Observers were blind to the scale while performing measurements but not to the type of applanator used. The appearance of the meniscus was assessed semiquantitatively. All measurements were combined and presented in a Bland-Altman plot.

Results A total of 140 eyes of 79 subjects were tested by seven observers. The range of measurements was $6-45 \mathrm{mmHg}$ (mean $17.8 \mathrm{mmHg}$ ) for the Goldmann applanator. On average, the Luneau SA applanator (range of measurements $4-36 \mathrm{mmHg}$ ) gave a measurement of $2.35 \mathrm{mmHg}$ less than the Goldmann standard. The standard deviation of these differences was $\mathbf{2 . 1 3} \mathbf{m m H g}$, giving an upper $95 \%$ confidence limit of $6.53 \mathrm{mmHg}$ and a lower $95 \%$ confidence limit of $-1.83 \mathrm{mmHg}$. The measurements agreed in only 24 out of 140 instances. In 28 eyes, the disposable tonometer end point was difficult to assess owing to excessively thick rings. Linear extrapolation suggests an increase in difference with increasing IOP.

Conclusion The inter-head inaccuracy, tendency to underestimate IOP, and lack of systematic inaccuracy make a corrective algorithm impossible to formulate. The range of variation between the Luneau SA disposable applanator and the Goldmann standard is sufficiently large to influence
\end{abstract}

clinical management decisions. We speculate that one explanation is the interaction of the tonometer with the tear film, making end point determination difficult. Further research is being undertaken.

Eye (2007) 21, 789-792; doi:10.1038/sj.eye.6702329; published online 21 April 2006

Keywords: Luneau SA; Goldmann; applanation tonometer

\section{Introduction}

The use of disposable instruments in the practice of ophthalmology has increased in response to fears of iatrogenic horizontal transmission of prion material between patients. It has been suggested that the very common practice of measurement of intraocular pressure (IOP) by Goldmann prism applanation tonometry may lead to transfer of potentially infective material. ${ }^{1-4}$ Because of this risk, the Medical Devices Agency has recommended that 'components of ophthalmic devices that touch the surface of the eye should be restricted to single patient use wherever practicable and where this does not compromise clinical outcome' ${ }^{4}$ There are a number of disposable applanation tonometers in use in the NHS. Silicone and acrylic disposable applanation tonometers have been the subject of previous study. Acrylic prisms (Tonosafe ${ }^{\circledR}$ ) were found to have good agreement with the Goldmann applanation tonometer, but silicone (Tonoshield $^{\circledR}$ ) prisms were found to consistently over read by a small margin. ${ }^{5}$

The Luneau SA disposable tonometer has become available. It is placed in the Goldmann tonometer device in the same way as the Goldmann prism. The objective of this study
Department of Ophthalmology, St Paul's Eye Unit, The Royal Liverpool University Hospital, Liverpool, UK

Correspondence: ACJ Baddon, Department of Ophthalmology, Walton Hospital, Rice Lane, Walton, Liverpool L9 1AE, UK Tel: + 7798607703 (Mobile), + 1514241559 (Home);

Fax: + 7798609051 .

E-mail: ophthalmologist@ onetel.com

Received: 10 May 2005 Accepted in revised form: 1 February 2006 Published online: 21 April 2006

No proprietary interests

No research funding

Presented as Poster and Quickfire Presentation, Royal College of Ophthalmologists Congress 2005 
was to compare the IOP readings of the two devices and to assess the end point features of each.

\section{Materials and methods}

The IOPs of a consecutive series of patients were measured with both the Luneau SA disposable applanator tonometer (Figure 1) and Goldmann applanator tonometer. Each patient's pressures were measured by only one of the seven observers. All observers were of consultant or specialist registrar grades. The type of applanator and the side measured first were alternated to eliminate systematic bias. The tonometers' calibration was checked before and after the study by use of the calibration bar. The measurements were made by setting the tonometer dial to zero and then applanating the cornea and aligning the inner aspect of the two half menisci. Measurements were taken with the

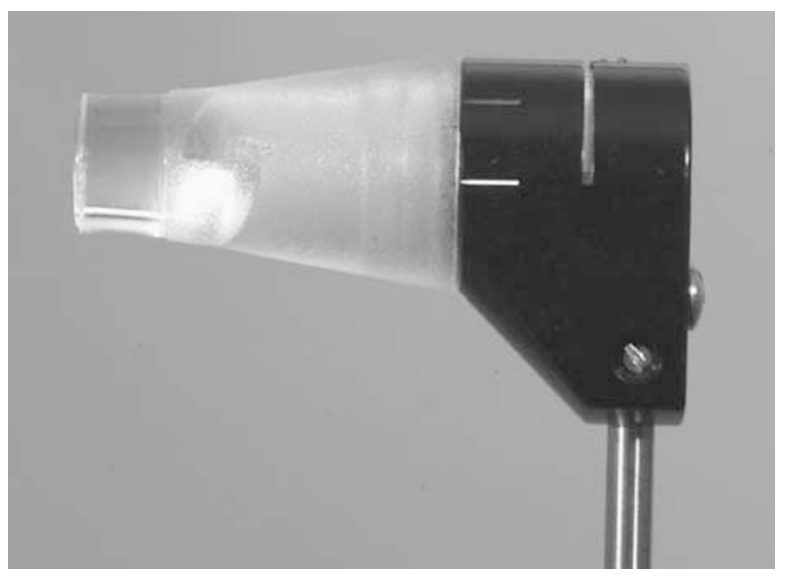

Figure 1 Luneau tonometer prism. eye in the primary position and apart from the applanation, there was no external pressure exerted on the eyeball. The observers were blinded to the scale on the tonometer dial. Observers were not blinded to the type of applanator being used. The appearance of the menisci was assessed semiquantitavely, without reference to a standard photograph, by all observers as too thin, too thick, or acceptable. To illustrate agreement, all measurements were combined and presented in a Bland-Altman plot ${ }^{6}$ with calculation of $95 \%$ confidence limits of agreement. A paired $t$-test was used to analyse the difference between measurements.

\section{Results}

A total of 140 eyes of 79 subjects were tested by seven observers. The range of measurements was $6-45 \mathrm{mmHg}$ (mean $17.7 \mathrm{mmHg}$ ) for the Goldmann applanator. The range of measurements for the Luneau SA applanator was $4-36 \mathrm{mmHg}$ (mean of $16.3 \mathrm{mmHg}$ ). On average, the Luneau SA applanator gave a measurement of $2.35 \mathrm{mmHg}$ less than the Goldmann standard. The range of difference in these paired readings was from -6 to $+9 \mathrm{mmHg}$. The standard deviation of these differences was $2.13 \mathrm{mmHg}$, giving an upper $95 \%$ confidence limit of $6.53 \mathrm{mmHg}$ and a lower $95 \%$ confidence limit of $-1.83 \mathrm{mmHg}$ for measurements made with the disposable prism in comparison to the Goldmann standard. The measurements agreed in only 24 out of 140 instances (Figure 2). A paired, two-tailed $t$-test showed that the difference between the means of the two data sets was very highly significant $(P<0.001)$ (Table 1$)$. In 28 eyes, the disposable tonometer end point was difficult to assess owing to excessively thick rings. In three eyes, thin poor quality rings were seen with the disposable tonometer. With these paired data removed, a paired

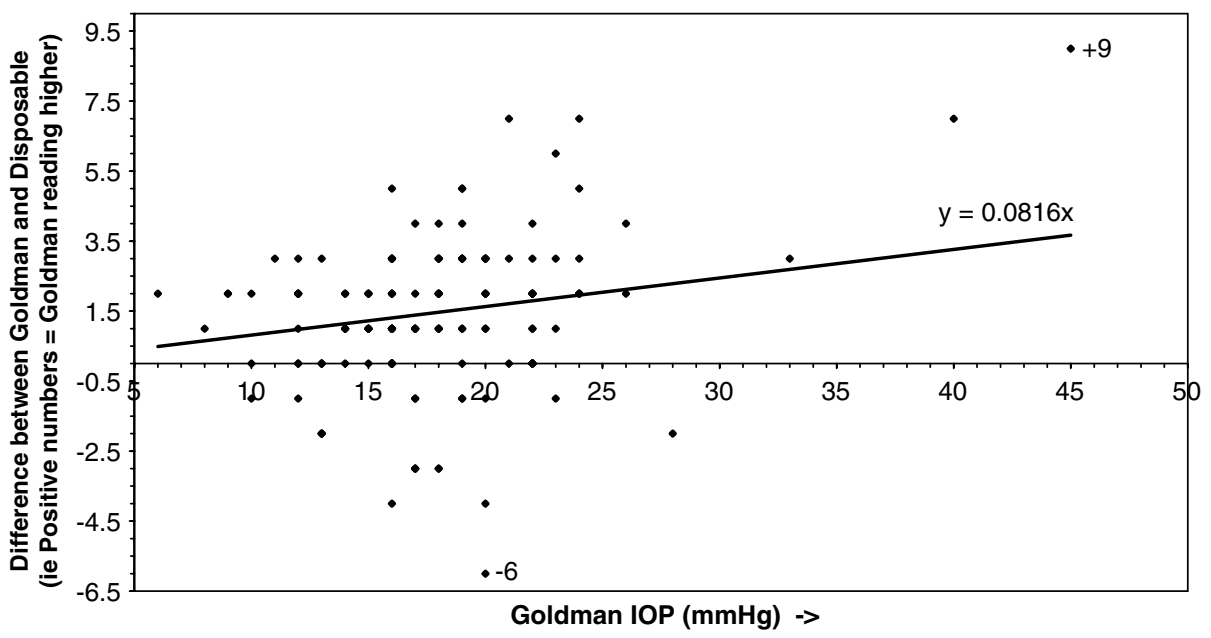

Figure 2 Bland-Altman plot. 
Table 1 Summary of results

\begin{tabular}{|c|c|c|c|}
\hline $\mathrm{N}=140$ eyes & $\begin{array}{l}\text { Goldmann } \\
\text { (G) }\end{array}$ & $\begin{array}{l}\text { Disposable } \\
\text { (D) }\end{array}$ & $\begin{array}{c}\text { Difference } \\
(\mathrm{G}-\mathrm{D})\end{array}$ \\
\hline Mean & 17.7 & 16.34 & 2.35 \\
\hline Standard deviation & & & 2.13 \\
\hline $95 \%$ CI & & & \pm 4.17 \\
\hline Range & 6 to 45 & 4 to 36 & -6 to +9 \\
\hline
\end{tabular}

For paired $t$-test, $t=13.69, P<0.001$.

All values are in $\mathrm{mmHg}$.

$t$-test shows that the statatistical significance remains high $(P<0.001)$. Linear extrapolation suggests an increase in measurement difference with increasing IOP.

\section{Discussion}

Our results show that, under conditions of normal clinical use, the Luneau SA disposable tonometer underestimates IOP compared with the reference standard Goldmann nondisposable tonometer in a nonsystematic way that, in many eyes, is clinically significant. While only $13.6 \%$ of our readings were above $21 \mathrm{mmHg}$, accurately recording a lower pressure may, in many cases, have clinical significance.

In this study, there was no measure made to assess inter-observer agreement. Neither were the observers blinded to the prism type, owing to the differing appearance of the Luneau SA disposable prism as compared to the Goldmann prism. Judgements on the quality of menisci were not standardised against photographs of a poor or satisfactory meniscus, although all observers were ophthalmologists who were very experienced in applanation tonometry.

Our findings are contrary to those of Maino et al, , who found good agreement between disposable and nondisposable tonometer prisms by practitioners trained in applanation tonometry; however, each eye received one applanation from each of the three types of prism in every case in random order. Our readings, although lesser in total number, were mostly within the normal range, from a population of a catchment area adjacent to that of Maino et al.

Our impression before setting up this study was that for the Luneau SA prism the end point of measurement, the alignment of the semicircular menisci, was difficult to determine because of the occurrence of thick rings. This impression is supported by observation in our results. The disposable prism menisci appearance was judged to be of acceptable quality in only $80 \%$ of cases, whereas there was no case of the Goldmann menisci reported as being of poor quality.

Goldmann applanation tonometry relies on the ImbertFick principle. Imbert-Fick states that the force of flattening $(F)$ equals the pressure $(P)$ multiplied by the surface area flattened $(A)$, or $F=P \times A$. However, this principle assumes that the surface is dry, perfectly flexible, infinitely thin, and spherical. In the design of the Goldmann applanator prism, two additional factors are included: the surface tension of the tear film, which tends to draw the tonometer head toward the cornea and corneal rigidity, and the tendency of the cornea to resist being flattened during applanation. Goldmann assumes the corneal thickness to be exactly $520 \mu \mathrm{m}$ and that all corneas are equally rigid with parallel anterior and posterior surfaces. Given these assumptions, at a diameter of applanation of $3.06 \mathrm{~mm}$, scleral rigidity and surface tension cancel each other out. ${ }^{8}$

We speculate that one aspect of the poor agreement between the Luneau SA and the Goldmann is the interaction between the prism and the tear film such that the surface tension is altered. Not only might this change the measurement of $\mathrm{IOP}^{8-11}$ but also may result in thick menisci that make end point determination inaccurate. We also speculate that different combinations of fluorescein and local anaesthetic agent might lead to a range of tear film surface tensions, which might affect the accuracy of the IOP measurement. Further studies are being undertaken to test these hypotheses.

Design of disposable applanation prisms may necessitate the use of different materials or the surface modification of current materials and this in turn might require the modification of the body of the tonometer or its dial. This modification would of course require that there be a systematic error. In the case of a nonconstant error in tonometry measurement, it would seem logical to balance the risk of horizontal transmission of infections between patients against the risk of the overor underestimation of their ocular pressure and the impact of this on treatment. The materials we received from Luneau did not include any specification as to the level of accuracy expected with their prism.

The inter-head inaccuracy, tendency to underestimate IOP, and lack of systematic inaccuracy make a corrective algorithm impossible to formulate. The range of variation between the Luneau SA disposable applanator and the Goldmann standard is sufficiently large to influence clinical management decisions. This lack of agreement means that the Luneau SA prism in its present form cannot replace the nondisposable prism.

\section{References}

1 Lim R, Dhillon B, Kurian KM, Aspinall PA, Fernie K, Ironside JW. Retention of corneal epithelial cells following Goldmann tonometry: implications for CJD risk. $\mathrm{Br} J$ Ophthalmol 2003; 87(5): 583-586. 
2 Manuelidis EE, Angelo JN, Gorgacz EJ, Kim JH, Manuelidis L. Experimental Creutzfeldt-Jakob disease transmitted via the eye with infected cornea. N Engl J Med 1977; 296: 1334-1336.

3 Walia JS, Chronister CL. Possible iatrogenic transmission of Creutzfeldt-Jakob disease via tonometer tips: a review of the literature. Optometry 2001; 72: 649-652.

4 Medical Device Agency AN 1999 (03). Single patient use of ophthalmic devices: implications for clinical practice. Medical Devices Agency, October 1999.

5 Bhatnagar A, Gupta AK. Disposable devices for measuring intraocular pressure: a clinical study to assess their accuracy. Eye 2005; 19(7): 752-754.

6 Bland JM, Altman DG. Statistical methods for assessing agreement between two methods of clinical measurement. Lancet 1986; 1: 307-310.
7 Maino AP, Uddin HJ, Tullo AB. A comparison of clinical performance between disposable and Goldmann tonometers. Eye 2005 [E-pub ahead of print].

8 Viernstein LJ, Pollack IP. Validity of the Imbert-Fick law for constant-pressure tonography. Exp Eye Res 1979; 29(6): 587-594.

9 Whitacre MM, Stein R. Sources of error with use of Goldmann-type tonometers. Surv Ophthalmol 1993; 38: 1-30.

10 Birchall W, Kumar V. A comparative study of proxymetacaine-fluorescein and lignocaine-fluorescein use during applanation tonometry. Br J Ophthalmol 2001; 85(4): 477-479.

11 Goel S, Chua C, Dong B, Butcher M, AhFat A, Hindi SK et al. Comparison between standard Goldmann applanation prism and disposable applanation prism in tonometry. Eye 2004; 18(2): 175-178. 